\title{
Role of Montelukast in Asthma and Allergic rhinitis patients
}

\author{
Faisal Faiyaz Zuberi' ${ }^{1}$ M. Amir Haroon², \\ Abdul Haseeb ${ }^{3}$, Shafi Muhammad Khuhawar ${ }^{4}$
}

\begin{abstract}
Objectives: Our objective was to evaluate the effect of Montelukast on the symptoms of asthma and allergic rhinitis (AR), assess its effect on the individual quality of life (QoL), and estimate the proportion of participants having adverse effects.

Methods: This prospective, open-label study conducted at Dow University of Health Sciences, Ankle Saria Hospital and Sindh Government Hospital Liaquatabad, Karachi, from August 2018 to September 2019, included patients aged $\geq 18$ years with a clinical diagnosis of Asthma, AR, or both. Patients were given a $10 \mathrm{mg}$ Montelukast tablet each day and then called for follow-up in the fourth week, where the questions related to the improvement in the symptoms of asthma or AR were asked. Patients were also asked about the improvement in QoL and any adverse effects.

Results: A total of 694 patients were registered of which $138(19.8 \%)$ had AR, 294(42.4\%) had asthma, while $273(39.3 \%)$ had both. Mean age was $41.1 \pm 14.63$ years and $352(50.7 \%)$ were male and $342(49.3 \%)$ were females. On a follow-up visit, there was a sufficient improvement in 351 asthmatics (63.9\%), and 288 patients with AR $(70.1 \%)$ overall, strong or marked improvement in the day $(n=342,62.3 \%)$ and night time $(n=331,60.3 \%)$ asthma symptoms. Overall improvements in QoL were very good or good in 419 patients. Montelukast was well-tolerated here with adverse effects (like abdominal discomfort, fever, fatigue, headache, rash, and upper respiratory tract symptoms) seen in 125 patients (18.01\%).

Conclusion: Montelukast was very effective in improving the symptoms and QoL of the individuals suffering from asthma and/or AR.
\end{abstract}

KEYWORDS: Allergic rhinitis, Asthma, Hypersensitivity, Montelukast, Quality of life.

How to cite this:

doi: https://doi.org/10.12669/pjms.36.7.2657

Zuberi FF, Haroon MA, Haseeb A, Khuhawar SM. Role of Montelukast in Asthma and Allergic rhinitis patients. Pak J Med Sci. 2020;36(7):1517-1522. doi: https://doi.org/10.12669/pjms.36.7.2657

This is an Open Access article distributed under the terms of the Creative Commons Attribution License (http://creativecommons.org/licenses/by/3.0), which permits unrestricted use, distribution, and reproduction in any medium, provided the original work is properly cited.

\section{INTRODUCTION}

Asthma and Allergic Rhinitis (AR) are the disorders affecting a large population of our society. ${ }^{1}$ Both of these conditions are often observed

\footnotetext{
Correspondence:

Dr. Faisal Faiyaz Zuberi, Associate Professor of Pulmonology, Head of Chest Unit-II

Dow University of Health Sciences, Karachi, Pakistan.

E-mail: faisal@zuberi.net

* Received for Publication:

* Revision Received:

* Revision Accepted:
}

April 9, 2020

September 9, 2020

September 15, 2020 together in the affected individuals, having mutual pathophysiology. Several mechanisms have been suggested to elaborate on their disease process with the involvement of inflammatory cells like mast cells and eosinophils, inflammatory mediators like leukotrienes, histamine, and tryptase. ${ }^{2}$ Asthma is a chronic inflammatory disorder of airways, presenting with variable symptoms related to the inflammation and hyper responsiveness of airways, while AR can present with rhinorrhea, enlargement of nasal turbinates and tenderness, conjunctival injection, and pallor. ${ }^{3,4}$ It is managed through minimizing the exposure to the allergen, pharmacotherapy, and immunotherapy. ${ }^{5}$ 
AR tops the list of the most commonly associated comorbidities with asthma as reported in the literature that $80 \%$ asthmatics also carry AR as a coexistent "ghost" diagnosis which in most cases remains underdiagnosed. ${ }^{6}$ A study from the United States reported AR symptoms in $72 \%$ of individuals with asthma, and interestingly 53\% of these subjects were undiagnosed with AR. Epidemiologically, overall the existence of asthma is $30 \%$ in patients primarily diagnosed with AR, while that of $A R$ is $70 \%$ in asthmatics. A similar kind of data from a study conducted in Japan reported the existence of AR in as many as $67.3 \%$ asthmatics. $^{7-9}$

Montelukast, a Leukotriene (LT) antagonist, has a therapeutic role in the treatment of Asthma and AR by acting on Cysteinyl leukotriene- 1 and 2 receptors. It is a widely used drug that was first approved in 1998 for use in the United States, indicated mostly in the prophylaxis and treatment of asthma, including the prevention of exercise-induced bronchoconstriction and AR with a recommended oral dosage of $10 \mathrm{mg}$ oncedaily in adults. ${ }^{10}$

Montelukast effectively improves the QoL by addressing the symptoms in the patients, proving to be a good replacement of drugs like inhaled corticosteroids (ICS) and long-acting beta2 agonists (LABA). As per a study published in 2019, it plays a great role in the improvement of QoL by addressing the symptoms potently, as compared with a placebo group. ${ }^{11}$

Asthma and AR lie in the category of conditions that need lifelong therapy because of the symptomatic relapses, which is a cause as well as a reason for the lack of compliance. A patient friendly mode of management was the need of the hour since so long. Montelukast came as the answer, a single-dose therapy along with many other advantages. We have focused on analysing the role of montelukast in two of the hypersensitivity disorders, along with sorting out all the pros of using this drug and assessing the traits that make it a first-line therapy in the aforementioned indications.

\section{METHODS}

This is a prospective, open-label study conducted at Dow University of Health Sciences, Ankle Saria Hospital and Sindh Government Hospital Liaquatabad Karachi, Pakistan, from August 2018 to September 2019. Both males and females, aged $\geq 18$ years with a clinical diagnosis of Asthma or AR giving informed consent were included in the study. Pregnant or breast-feeding patients, those having a history of previous adverse reactions to montelukast, history of hyper-eosinophilic disorder other than an atopic disease, or any significant active pulmonary pathology other than asthma were excluded. The study was approved by the institutional review board (No.: DUHS/IRC/2018-003). The trial was also registered at www.clinicaltrials.gov. (Identifier: NCT03380975).

When patients signed the informed consent, a brief history was taken at registration. They were asked about the diagnosis and its symptoms, either having asthma, AR, or both. The severity of asthma was divided into categories of intermittent and persistent (mild, moderate, and persistent) according to recent guidelines. ${ }^{12}$ While AR was categorized as intermittent or persistent based on the duration of symptoms. ${ }^{13}$ Individual quality of life (QoL), assessment about sleep, work, everyday life, and physical activity was done at registration.

Patients were given a $10 \mathrm{mg}$ Montelukast tablet (Aireez $\left.{ }^{\circledR}\right)$, each day and then called for follow-up in the fourth week. On a follow-up visit, general improvement in asthma and AR symptoms, improvement of day and night-time asthma symptoms, and specific improvement in AR symptoms were evaluated. General improvements were categorized as very good, good, satisfactory, sufficient, or not sufficient. Specific improvements in symptoms or QoL domains were categorized as strong, marked, moderate, or none. Patients were also asked about the improvement in QoL and any adverse effects occurring during the therapy. All adverse events occurring during the study period were recorded.

Data were entered and analysed by using SPSS version 23.0, where frequency and percentages were calculated for gender, family history, the severity of asthma and AR, concomitant medications usage, symptoms, Qol categories, adverse effects of montelukast, and improvement in symptoms and QoL.

\section{RESULTS}

A total of 694 patients were included in the study from August 2018 to September 2019 after taking informed consent. In terms of diagnosis, 
Table-I: Patient baseline characteristics at week $4(n=694)$.

\begin{tabular}{|c|c|}
\hline Characteristic & $n(\%)$ \\
\hline \multicolumn{2}{|l|}{ Gender } \\
\hline Male & $352(50.7)$ \\
\hline Female & 342(49.3) \\
\hline Duration (Mean \pm SD) of disease & $31.08 \pm 61.69$ \\
\hline Family History of Asthma & 204(29.4) \\
\hline \multicolumn{2}{|l|}{ Diagnosis } \\
\hline Asthma alone & $294(42.4 \%)$ \\
\hline Allergic rhinitis alone & $138(19.8 \%)$ \\
\hline Asthma and Allergic rhinitis & $273(39.3 \%)$ \\
\hline \multicolumn{2}{|l|}{ Asthma $(n=549)$} \\
\hline Intermittent & $185(33.7)$ \\
\hline Mild & $203(36.9)$ \\
\hline Moderate & $161(29.3)$ \\
\hline \multicolumn{2}{|l|}{ Allergic Rhinitis $(n=411)$} \\
\hline Intermittent & $243(59.1)$ \\
\hline Persistent & $169(41.1)$ \\
\hline \multicolumn{2}{|l|}{ Concomitant Medications } \\
\hline Antileukotrienes & $286(41.2)$ \\
\hline Inhaled Corticosteroids & $217(31.3)$ \\
\hline Oral Corticosteroids & $140(20.2)$ \\
\hline Long-acting inhaled beta2-agonists & $81(11.7)$ \\
\hline Short-acting inhaled beta2-agonists & $42(6.1)$ \\
\hline Short-acting oral beta2-agonists & $49(7.1)$ \\
\hline Ipratropium & $163(23.5)$ \\
\hline Theophylline & $206(29.7)$ \\
\hline Others & $32(4.6)$ \\
\hline Average inhaler Puff per day \pm SD & $2.60 \pm 1.03$ \\
\hline
\end{tabular}

138(19.8\%) had AR, 294(42.4\%) had asthma, while $273(39.3 \%)$ had both. The mean \pm SD of age was $41.1 \pm 4.63$ years which included $50.7 \%$ males and $49.3 \%$ females. The majority of participants $(62.4 \%, \mathrm{n}=433)$ had no family history of asthma. When the severity of asthma and AR were assessed, most of them had a persistent disease with further categorization as shown in Table-I. Montelukast tablet was given to all the patients despite their ongoing medications, details of which are presented in Table-I.

Almost the entire study population showed both the day and night-time symptoms on presentation, with cough being the most prevalent one. On a follow-up visit, there was a sufficient improvement in 351 asthmatics $(63.9 \%)$, strong or marked improvement in the day $(n=342,62.3 \%)$ and nighttime $(n=331,60.3 \%)$ asthma symptoms (Table-II).

The symptoms of AR were variable including sneezing, runny nose, nasal congestion, watery
Table-II: Symptoms of patients with asthma before and after administration of montelukast at Week $4(\mathrm{n}=549)$.

\begin{tabular}{lc}
\hline Characteristic & $n(\%)$ \\
\hline On presentation & \\
Day-time asthma symptoms & \\
Cough & $528(95.1)$ \\
Wheezing & $440(79.3)$ \\
Chest tightness & $382(68.8)$ \\
Shortness of breath & $322(58.0)$ \\
Others & $1(0.1)$ \\
Night-time asthma symptoms & \\
Cough & $507(91.4)$ \\
Shortness of breath & $407(73.3)$ \\
Nocturnal awakening & $266(47.9)$ \\
Others & $2(0.2)$ \\
On follow- up & \\
Improvement in day symptoms of asthmatics \\
Strong & $233(42.4)$ \\
Marked & $109(19.8)$ \\
Moderate & $78(14.2)$ \\
None & $4(0.7)$ \\
Improvement in night symptoms of asthmatics \\
Strong & $196(35.7)$ \\
Marked & $135(24.6)$ \\
Moderate & $77(14.0)$ \\
None & $7(1.2)$ \\
Asthma overall improvement & \\
Very good & $182(33.1)$ \\
Good & $169(30.7)$ \\
Suffisfactory & $45(8.1)$ \\
Not sufficient & $23(4.1)$ \\
& $5(0.7)$ \\
\hline
\end{tabular}

eyes, and red/burning eyes. On a follow-up visit, there was a sufficient improvement in 288 patients of AR (70.1\%) (Table-III). Overall improvements in QoL were very good or good in 419 patients (Table-IV).

As per our results, Montelukast was welltolerated here since in this large group of patients, 125 patients $(18.01 \%)$ had one or more adverse effects reported including abdominal discomfort $(2.6 \%, \mathrm{n}=18)$, fever $(2.2 \%, \mathrm{n}=15)$, fatigue $(5.2 \%$, $n=36)$, headache $(5.6 \%, n=39)$, rash $(1 \%, n=7)$, and symptoms of upper respiratory tract infection $(1.4 \%, \mathrm{n}=10)$.

\section{DISCUSSION}

The participants involved in our study showed a marked improvement in their QoL which was significantly affected before the commencement of 
Table-III: Symptoms of patients with Allergic Rhinitis before and after administration of Montelukast at week 4 .

\begin{tabular}{|c|c|c|}
\hline Characteristic & & $n(\%)$ \\
\hline \multicolumn{3}{|l|}{ On presentation } \\
\hline \multirow{6}{*}{$\begin{array}{l}\text { Allergic rhinitis } \\
\text { symptoms }\end{array}$} & Sneezing/itching & $356(64.1)$ \\
\hline & Runny nose & $310(55.9)$ \\
\hline & Nasal congestion & $269(48.5)$ \\
\hline & Watery eyes & $145(26.1)$ \\
\hline & Red/burning eyes & $119(21.4)$ \\
\hline & Others & - \\
\hline \multicolumn{3}{|l|}{ On follow-up } \\
\hline \multirow[t]{4}{*}{ Sneezing } & Strong & $94(22.9)$ \\
\hline & Marked & $72(17.5)$ \\
\hline & Moderate & $89(21.6)$ \\
\hline & None & $61(14.8)$ \\
\hline \multirow[t]{4}{*}{ Runny nose } & Strong & $102(24.8)$ \\
\hline & Marked & $62(15.1)$ \\
\hline & Moderate & $37(9.0)$ \\
\hline & None & $107(26.0)$ \\
\hline \multirow[t]{4}{*}{ Nasal } & Strong & $80(19.5)$ \\
\hline & Marked & $68(16.5)$ \\
\hline & Moderate & $62(15.1)$ \\
\hline & None & $94(22.9)$ \\
\hline \multirow[t]{4}{*}{ Watery eyes } & Strong & $79(19.2)$ \\
\hline & Marked & $51(12.4)$ \\
\hline & Moderate & $32(7.8)$ \\
\hline & None & $119(28.9)$ \\
\hline \multirow[t]{4}{*}{ Red eye } & Strong & $82(19.9)$ \\
\hline & Marked & $43(10.5)$ \\
\hline & Moderate & $29(7.1)$ \\
\hline & None & $121(29.4)$ \\
\hline \multirow{5}{*}{$\begin{array}{l}\text { Allergic rhinitis } \\
\text { overall } \\
\text { improvement }\end{array}$} & Very good & $82(19.9)$ \\
\hline & Good & $130(31.6)$ \\
\hline & Satisfactory & $58(14.1)$ \\
\hline & Sufficient & $18(4.4)$ \\
\hline & Not Sufficient & $6(1.4)$ \\
\hline
\end{tabular}

the treatment with montelukast. Overall, a strong improvement was observed in the day, night and overall symptoms of asthma. Moreover, the majority of participants also showed improvement in AR symptoms on the follow-up i.e. sneezing, cough, nasal, and ocular ones.

Our study is similar to the work of Philip G et al., where marked improvement was observed in nasal and ocular symptoms after the two weeks treatment with montelukast $10 \mathrm{mg}$, the same study also concluded that this significant reduction in the symptoms of AR imposed a positive impact on asthma-related problems of the patient who were dealing with both the
Table-IV: Individual Quality of life assessment before and after administration of Montelukast at week 4 .

\begin{tabular}{|c|c|c|}
\hline Characteristic & & $n(\%)$ \\
\hline \multicolumn{3}{|l|}{ On presentation } \\
\hline \multirow[t]{3}{*}{ Difficulty sleeping } & Mild & $391(58.6)$ \\
\hline & Moderate & $238(35.7)$ \\
\hline & Severe & 38(5.7) \\
\hline \multirow[t]{3}{*}{ Difficulty with job } & Mild & $336(48.7)$ \\
\hline & Moderate & $330(47.8)$ \\
\hline & Severe & $24(3.7)$ \\
\hline \multirow{3}{*}{$\begin{array}{r}\text { Difficulty with } \\
\text { everyday life }\end{array}$} & Mild & $341(49.6)$ \\
\hline & Moderate & $315(45.8)$ \\
\hline & Severe & $32(4.7)$ \\
\hline \multirow{3}{*}{$\begin{array}{l}\text { Limitations to } \\
\text { daily activities }\end{array}$} & Mild & $268(39.4)$ \\
\hline & Moderate & $306(44.9)$ \\
\hline & Severe & 107(15.7) \\
\hline \multicolumn{3}{|l|}{ Follow-up visit } \\
\hline \multirow[t]{4}{*}{ Sleeping } & Strong & $158(29.1)$ \\
\hline & Marked & $94(17.3)$ \\
\hline & Moderate & $81(14.9)$ \\
\hline & None & $210(38.7)$ \\
\hline \multirow[t]{4}{*}{ Job } & Strong & $153(28.2)$ \\
\hline & Marked & $92(16.9)$ \\
\hline & Moderate & $150(27.6)$ \\
\hline & None & $148(27.3)$ \\
\hline \multirow[t]{4}{*}{ Everyday } & Strong & $118(21.7)$ \\
\hline & Marked & $124(22.8)$ \\
\hline & Moderate & $123(22.7)$ \\
\hline & None & $178(32.8)$ \\
\hline \multirow[t]{4}{*}{ Daily activities } & Strong & $137(25.2)$ \\
\hline & Marked & $113(20.8)$ \\
\hline & Moderate & $75(13.8)$ \\
\hline & None & $218(40.1)$ \\
\hline \multirow[t]{3}{*}{ Overall assessment } & Good & $336(61.9)$ \\
\hline & Satisfactory & $187(34.4)$ \\
\hline & Reduced & $20(3.7)$ \\
\hline \multirow[t]{5}{*}{ Improvement } & Very good & $195(35.9)$ \\
\hline & Good & $224(41.3)$ \\
\hline & Satisfactory & $81(14.9)$ \\
\hline & Sufficient & $35(6.4)$ \\
\hline & Not Sufficient & $8(1.5)$ \\
\hline
\end{tabular}

disorders. ${ }^{14}$ Montelukast particularly has a positive impact on cough and all the discomforts associated with it, ${ }^{15}$ and this is quite evident in our patients as well.

After the computation of results, headache was found to be the most prevalent among all the adverse effects of this LT antagonist. Findings of 
Haarman MG et al. somewhat validates this as they also reported headache as the most common adverse effect along with others like abdominal pain, aggression, abnormal behaviour, rash, and muscle spasm. ${ }^{16}$

The mainstay in the management of asthma has always been ICS with or without LABA. However, many asthmatics were not in the complete symptom-free state after the use of this combination. Thus the Global initiative for Asthma came up with upgrading the guidelines and included add-on therapy with LT modifiers in the management of asthma. ${ }^{17}$ These comprise of two main groups of CysLT1R antagonist (like montelukast, pranlukast, and zafirlukast) and 5-lipoxygenase inhibitors (like zileuton). ${ }^{18}$ As far as AR is concerned, montelukast maintains the balance in nitric oxide production, imbalance of which is believed to be one of the contributors in AR pathogenesis. ${ }^{16}$ As computed in our results, other authors have also demonstrated a good role of LT receptor antagonists in the management of asthma and AR symptoms. Once-daily oral dosage of montelukast significantly improves the airway function in asthmatics. ${ }^{19}$ Similarly, it also proves beneficial in reducing daytime ocular symptoms with a delayed impact on night-time symptoms of AR. ${ }^{20}$

There are several reasons that make montelukast stand out as a part of the treatment regimen of asthma and AR and the topmost of them is the ease in compliance for the patient as it is far easier to use a drug once-daily orally in comparison with other drugs. Secondly, this also shortens the extended side-effect profile (like that after longterm steroid usage).

Limitations of the study: Although this study has tried to cover the role of montelukast in the treatment of asthma and AR but there are some limitations that can be listed in order to get worked on in the future, as the evaluation of short and long-term side effects associated with the use of montelukast, contraindications, toxicities, and continuous monitoring of the patient while on treatment. There was no control group or a placebo drug to compare the effects and be sure that the outcome is only due to the tested drug. Further research is needed in order to emphasize the importance and safety of this drug. Moreover, there is some gap in research regarding the role of montelukast in the treatment of several other allergic disorders to consolidate the theories behind the mechanisms and adverse effects of its use in these conditions.

\section{CONCLUSION}

Montelukast is effective in improving the symptoms and QoL of the individuals suffering from asthma and Allergic Rhinitis.

Source of Funding: None.

Conflict of interest: None.

\section{REFERENCES}

1. Benninger M, Waters $H$. Montelukast: Pharmacology, Safety, Tolerability and Efficacy. Clin Med Ther. 2009;1:1253-1261. doi: 10.4137/CMT.S1147

2. Khan DA. Allergic rhinitis and asthma: Epidemiology and common pathophysiology. Allergy asthma Proc. 2014;35(5):357-361. doi: 10.2500/aap.2014.35.3794

3. Bunyavanich S, Soto-Quiros ME, Avila L, Laskey D, Senter JM, Celedon JC. Risk factors for allergic rhinitis in Costa Rican children with asthma. Allergy. 2010;65(2):256-263. doi: 10.1111/j.1398-9995.2009.02159.x

4. Nakagome K, Nagata M. Pathogenesis of airway inflammation in bronchial asthma. Auris Nasus Larynx. 2011;38(5):555-563. doi: 10.1016/j.anl.2011.01.011

5. May JR, Dolen WK. Management of Allergic Rhinitis: A Review for the Community Pharmacist. Clin Ther. 2017;39(12):2410-2419. doi: 10.1016/j.clinthera.2017.10.006

6. Egan M, Bunyavanich S. Allergic rhinitis: the "Ghost Diagnosis" in patients with asthma. Asthma Res Pract. 2015;1:8. doi: 10.1186/s40733-015-0008-0

7. Ohta K, Bousquet PJ, Aizawa H, Akiyama K, Adachi M, Ichinose $M$, et al. Prevalence and impact of rhinitis in asthma. SACRA, a cross-sectional nation-wide study in Japan. Allergy. 2011;66(10):1287-1295. doi: 10.1111/j.13989995.2011.02676.x

8. Grossman J. One airway, one disease. Chest. 1997;111(2): 11S-16S. doi:10.1378/chest.111.2_supplement.11s

9. Esteban CA, Klein RB, Kopel SJ, McQuaid EL, Fritz GK, Seifer R, et al. Underdiagnosed and Undertreated Allergic Rhinitis in Urban School-Aged Children with Asthma. Pediatr Allergy Immunol Pulmonol. 2014;27(2):75-81. doi: 10.1089/ped.2014.0344

10. Montelukast. In: LiverTox: Clinical and Research Information on Drug-Induced Liver Injury [Internet]. Bethesda (MD): National Institute of Diabetes and Digestive and Kidney Diseases; 2012. Available from: https://www.ncbi.nlm.nih.gov/books/NBK548264/

11. Baig S, Khan RA, Khan K, Rizvi N. Effectiveness and Quality of Life with Montelukast in Asthma - A double-blind randomized control trial. Pak J Med Sci. 2019;35(3):731-736. doi: $10.12669 /$ pjms.35.3.42

12. Expert Panel Report 3 (EPR-3): Guidelines for the Diagnosis and Management of Asthma-Summary Report 2007. J Allergy Clin Immunol. 2007;120(5):S94-138. doi:10.1016/j.jaci.2007.09.043

13. Small P, Keith PK, Kim H. Allergic rhinitis. Allergy Asthma Clin Immunol. 2018;14(2):S31-4151. doi:10.1186/ s13223-018-0280-7 
14. Philip G, Nayak AS, Berger WE, Leynadier F, Vrijens F, Dass SB, et al. The effect of montelukast on rhinitis symptoms in patients with asthma and seasonal allergic rhinitis. Curr Med Res Opin. 2004;20(10):1549-1558. doi: 10.1185/030079904X3348

15. Mincheva RK, Kralimarkova TZ, Rasheva M, Dimitrov Z, Nedeva D, Staevska M, et al. A real - life observational pilot study to evaluate the effects of two-week treatment with montelukast in patients with chronic cough. Cough. 2014;10(1):2. doi: 10.1186/17459974-10-2

16. Haarman MG, van Hunsel F, de Vries TW. Adverse drug reactions of montelukast in children and adults. Pharmacol Res Perspect. 2017;5(5). doi: 10.1002/prp2.341

17. Gao J, Cai F, Peng M, Ma Y, Wang B. Montelukast improves air trapping, not airway remodeling, in patients with moderate-to-severe asthma: a pilot study. Chin Med J (Engl). 2013;126(12). doi: 10.3760/ cma.j.issn.0366-6999.20121888

18. Scichilone N, Battaglia S, Benfante A, Bellia V. Safety and efficacy of montelukast as adjunctive therapy for treatment of asthma in elderly patients. Clin Interv Aging. 2013;8:1329-1337. doi: 10.2147/CIA.S35977

19. Naqvi SHR, Rukh M, Siddiqui FA, Rehman I Bin. Role of leukotriene receptor antagonist in acute severe attack of bronchial asthma in comparison with conventional therapy. Pak J Pharmacol. 2011;28(2):13-21.
20. Ansari M, Ansari N, Junejo S. Montelukast versus nigella sativa for management of seasonal allergic rhinitis: A single blind comparative clinical trial. Pak J Med Sci. 2010;26(2):249-254.

\section{Authors' Contributions:}

FFZ: Worked on concept and design of study and questionnaire and he is also the responsible and accountable for the accuracy or integrity of the work.

MA, AH, SM: Contributed in data collection and reviewed the paper. They are also responsible and accountable for the accuracy and integrity of the work

All authors have read and approved the final draft of the manuscript.
Authors:

1. Dr. Faisal Faiyaz Zuberi, M.B.B.S., F.C.P.S (Med)., F.C.P.S (Pulm), FCCP

Associate Professor Pulmonology,

Head of Chest Unit-II,

Dow University of Health Sciences,

Karachi, Pakistan.

2. Dr. M. Amir Haroon, M.B.B.S., D.T.C.D., M.D.

Pulmonologist and Consultant Physician,

Sindh Government Hospital Liaquatabad, Karachi, Pakistan.

3. Dr. Abdul Haseeb, M.B.B.S., D.T.C.D (UK)., M.C.P.S (Chest). Consultant Chest Specialist, Jamal Noor Hospital, Karachi, Pakistan.

4. Dr. Shafi Muhammad Khuhawar, M.B.B.S., F.C.P.S., M.C.P.S. Associate Professor, Pulmonology, Ghulam Muhammad Mahar Medical College, Sukkur, Pakistan. 